\title{
Assessment: Classic and Innovative Approaches
}

\author{
Marion G. Ben-Jacob \\ Department of Mathematics and Computer Sciences, Mercy College, Dobbs Ferry, USA \\ Email: mbenjacob@mercy.edu
}

How to cite this paper: Ben-Jacob, M.G. (2017) Assessment: Classic and Innovative Approaches. Open Journal of Social Sciences, 5, 46-51.

http://dx.doi.org/10.4236/jss.2017.51004

Received: November 22, 2016

Accepted: January 3, 2017

Published: January 6, 2017

Copyright $\odot 2017$ by author and Scientific Research Publishing Inc. This work is licensed under the Creative Commons Attribution International License (CC BY 4.0).

http://creativecommons.org/licenses/by/4.0/

\begin{abstract}
This paper explores the goals of assessment for today and for the future, addressing different categorizations of assessment. It approaches each category of assessment from the perspective of its objectives. It then proceeds to examine why the popular forms of educational assessment are lacking for the preparation of our students to become independent thinkers and successful lifelong learners. A suggested strategy to ameliorate the situation is presented.
\end{abstract}

\section{Keywords}

Academic Assessment, Traditional Methods, Innovation, Lifelong Learning

\section{Introduction}

Assessment is an important factor of improved education on the part of faculty, students, and programs. It provides feedback from which those involved can learn and make the necessary changes to enhance the learning environment. The paper discusses some innovative approaches that have been attempted at different institutions as well. It provides an approach to assessment that will enhance the preparation of our students for future success as creative and analytic learners of the future. The paper is structured in sections that discuss the following: the classification and goals of standard approaches to assessment, enhanced preparation of our students for lifelong learning and the associated assessment of it, a model of how to accomplish the aforementioned, and a conclusion.

\section{Classification and Goals of Assessment}

Educational assessment is the amount of knowledge, skills, or beliefs in terms that can be accounted for or measured. Educational assessment should be based on the foundation of the knowledge and the process of learning (Ben-Jacob \& Ben-Jacob, “Assessment," 2014, [1], “Alternative Assessment Methods," 2014) [2]. 
Assessment is divided into initial, formative, and summative types. Initial assessment is the amount of knowledge and skill level exhibited at the beginning of a learning environment. It is used as a benchmark for the progress made in the educational process. Formative assessment is the measurement of progress made as the material unfolds. Summative assessment measures the progress made at the end of the time period allotted (Ben-Jacob \& Ben-Jacob, “Assessment," 2014, [1], “Alternative Assessment Methods," 2014 [2]).

Assessment is also categorized by objective versus subjective. The simplest determination is that objective assessment has one answer and subjective has more than one. Objective question types include true/false multiple choice and multiple-response, etc. Subjective questions include extended-response questions and essays (Ben-Jacob \& Ben-Jacob, “Assessment," 2014, [1], “Alternative Assessment Methods," 2014 [2]). We contend that it is the latter type that develops a stronger preparation for the future ability of our students in their professional lives.

There is also formal versus informal delineation of assessment. Informal assessment is based on observation and discussion whereas formal assessment encourages a written evaluation. Formal assessment uses supporting data on which to base conclusions (Weaver, 2013) [3].

The goals are similar, if not the same for all types of assessment. Betterment or improvement of student learning is the ultimate target (Palomba \& Banta, 1999) [4]. Success can be demonstrated in different ways, including higher grades on exams, improved writing skills on papers and essays, and more cogent verbal discussion on the part of the student. From a pedagogical perspective, success of assessment can be gauged by changes in teaching styles, assignments, and projects that enhance the outcomes of student learning.

\section{Course Assessment}

We will discuss a basic freshmen mathematics course and a basic freshman English course for the sake of comparison. We will address the standardly designed methods of assessment and then suggest strategies to improve upon them.

Mathematics is a universal language and not a subjective discipline. An answer to a problem is correct or incorrect. The process of an algorithm used in solving a problem is critical as it should work for all problems of the same ilk.

Assessment on the part of the instructor is often based on the amount of credit placed on the midterm and final exam. Perhaps greater emphasis should be placed on formative assessment. This would entail regularly scheduled quizzes on small portions of the material. Our contention is that even if one believes strongly in formative assessment, significant emphasis needs to be place on a final exam. Quiz grades can let students know which topics they have mastered and what they still need to review, but if one does not retain the information from a basic math course at the end of the semester, it will be difficult to succeed in the next course. Mathematics builds on itself content-wise (Ben-Jacob \& BenJacob, “Assessment,” 2014, [1], “Alternative Assessment Methods,” 2014 [2]). 
Assessment in a basic English course is more subjective. The usual components include comprehension, grammar and expression of thought. The classic example of the subjective nature of assessment is the situation where two students turn in the same paper to two different instructors. One gets an $A$ and the other gets a $C$. The latter student questions his grade and receives the response, "It is your style of writing that needs work." A grading rubric in such a course needs to be as explicit as possible. As for comprehension, a specific percentage can be allotted to participation in classroom discussion and to the content of essays and papers. Explicit percentages can be articulated for grammar, format, documentation and style of citation. Given a specific rubric, the students can achieve higher grades, knowing where to emphasize their work, i.e. on their weaker areas (Ben-Jacob \& Ben-Jacob, "Assessment," 2014, [1], "Alternative Assessment Methods," 2014 [2]).

Again, consideration has to be given to focusing on summative or formative assessment. Perhaps, the institution wants to see how far the students can improve if it is a basic course. Even if this is true, we believe that a certain benchmark must be achieved by the end of the semester, i.e. summative assessment is important as well. Independent of one's major, a student needs to be able to write in a clear, grammatical way in order to succeed in advanced studies and in a profession.

It is worthy of note that some institutions have modified standard means of assessment. Innovative tactics are geared to improve student learning and provide accountability for the institution

With the progress of technology, ePortfolios for each student allowing him to include a sampling of his achievement on different projects, illuminating different talents, are being used. Rubrics or guides for assessing students' work which serve as an across-the-board fair measurement are popular as well. Online assessment groups allow for sharing of ideas and for greater uniformity across the nation (Banta, T., Griffin, M., Flateby, T., Kahn, S., 2009) [5]. All of the aforementioned are commendable but do not address the need for preparing our students for the type of work and assessment they will be doing in the future. Educators need to refer to Bloom's Taxonomy and focus on assessing the type of work that supports creativity and independent learning.

One of the most difficult aspects of teaching is determining how to help students make the transition from being passive recipients of information toward a state in which they know what questions to ask, how to ask them, and how to deal with the response. These are the foundation skills for life-long learning and the key to success in the workplace. These are precisely the abilities that define the inquiring learner.

The goal for educators is to create a climate that fosters inquiry and independent learning among students. We want to sharpen the skills of observation, analysis, and communication. When pursued in a group, we also want the students to be able to work as a team. We want to train and encourage independent learners. 
Unfortunately, the way that assessment is used in today's educational environment, stymies the aforementioned goals of how we want to prepare our students for their futures. In order to support this position, we first have to review Bloom's Taxonomy (Figure 1), a framework for categorizing educational goals.

Assessment design today focuses on the lowest level of the taxonomy-what do the students remember. It concentrates on what the students can regurgitate as opposed to problem solving. It is not linked to future performance. It does not measure a level of creativity. Most of the examinations that are administered today are reflective of inauthentic problem solving. To arrive at a creative solution, students need to try different approaches, fail at most of them and then arrive at some new or original work.

Assessment today is most likely the application of rote procedures. We rank and classify students based on what they can remember from the course material as opposed to how they are developing as independent thinkers and learners. As it stands today assessment is a barometer for students to know what they must review to get a good grade.

The algorithm for helping our students is to consider things in reverse of what we have been doing. We are used to deciding on course content and covering that material in class. Then, we administer exams and projects that reflect that content. To prepare our students for the future we need to work in the other direction. As pedagogue we need to first determine what the desired outcomes are for our students. Next we need to determine what would be acceptable evidence that these outcomes have been achieved and to what degree, and lastly, decide on an acceptable approach to attain this evidence.

When we work at an innovative level, to create a new or original work, or to evaluate the work or design of someone else, we can use tools like books, Google, and opinions and ideas of our peers. When students are assessed now, if we collaborate with others or use texts under most circumstances, most of the time, it is considered cheating.

In order to be creative one needs to make assumptions about a situation and

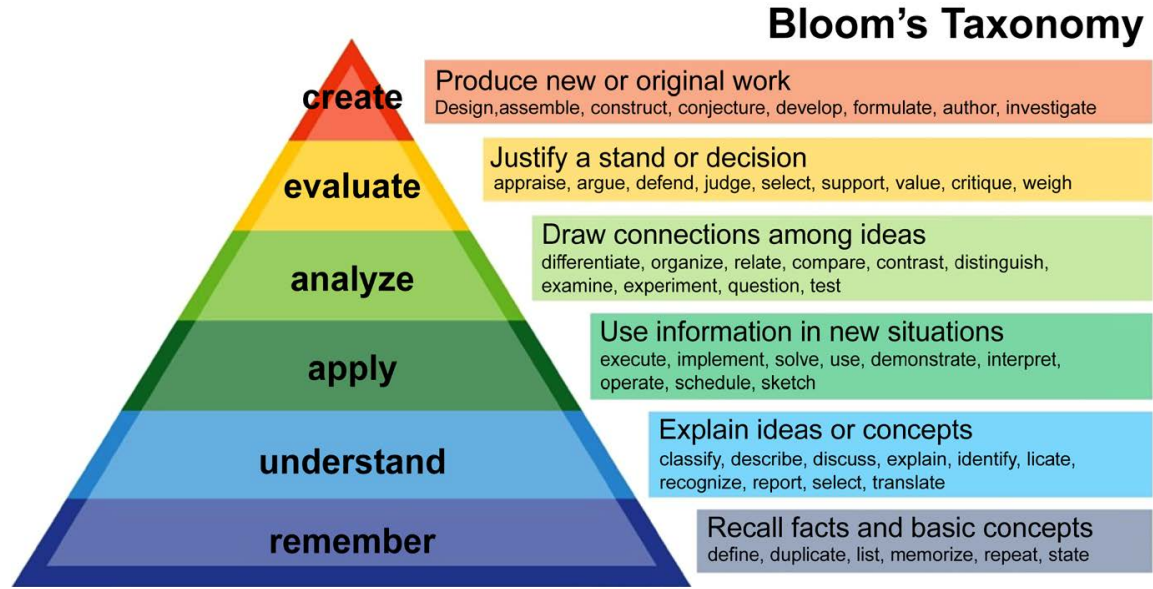

Figure 1. Bloom's Taxonomy is a classification of human cognition critical to the process of learning (Vanderbilt, 2016) [6]. 
then adjust the hypotheses if necessary. This is reflected in mathematical modeling. Mathematical modeling describes a system or environment or situation using mathematical terminology. Certain assumptions for the model which may or may not be true are made. After the model is developed, the assumptions can be changed, developing a more accurate model. Mathematical modeling is used in different disciplines to help explain an entire environment, to determine the status of its components, and to make predictions ("Business", 2013) [7].

Yet, most students today are afraid to make assumptions. They would rather go the "safe route" and solve problems or write essays the way described in class. We need to broaden the horizons of our students in order to prepare them for the future. We need to encourage them to take educated guesses when necessary.

One approach is to assign questions on an exam or project for which students can use references as they see fit. The problems involved would be based on the course content as a foundation but creativity would be necessary on the part of the student. One might also assign group work to be assessed. The usual difficulty with a group project is who did what part and how much of the work. This can be overcome by asking each member of the group how they divided up the work, piecewise or collectively on each section of the project. In the latter case, each group member could be asked in confidentiality what percentage each member of the team contributed. In the professional world, teamwork is a given, your team may not be chosen by you, and each team member may not put the same amount of effort forward either.

If we elaborate on the aforementioned and want to be able to judges individual accomplishments, we can proceed as follows. This strategy for assessing our students and preparing them for their future goals is to give an individual assignment based on the concepts introduced in the course. The students should be allowed to use outside sources, e.g. the Internet, additional texts. The class can then do a group assignment, once again with the use of outside sources. In a group, we know that some students will "carry" the weaker ones. The next assignment should be individual with the use of external sources permissible. Each of the assignments should not be based on rote repetition of the material covered in class, but rather its application. This strategy will allow us to measure the progress of an individual student and realize the degree to which the group work aided.

\section{Conclusion}

The goal of this paper is to bring to light the importance of assessment in the academic environment. Student self-assessment and rubrics for assessing the performances of students are fundamental for academic success. The improvement must come via what we assess if we are to prepare our students for their future endeavors and to make them successful lifelong learners. Evaluating them just on the material covered in class or in the text is not sufficient. We need to encourage creativity. We need to assess the higher levels of learning of Bloom's' Taxonomy. The approach presented can only help charter the course for enhanced 
academic performance, and greater preparation for future learning and professional performance.

\section{References}

[1] Ben-Jacob, M. and Ben-Jacob, T. (2014) Assessment: Categorizations, Supporting Technologies, and a Model for Betterment. Pensee Journal, 76, Issue 7.

[2] Ben-Jacob, M. and Ben-Jacob, T. (2014) Alternative Assessment Methods Based on Categorizations, Supporting Technologies and a Model for Betterment. International Conferences on Educational Technologies 2014 and Sustainability, Technology and Education 2014. http://files.eric.ed.gov/fulltext/ED557348.pdf

[3] Weaver, B. (2013) Formal vs. Informal Assessments. Scholastic, Inc. https://beta.scholastic.com/teachers/articles/teaching-content/formal-vs-informal-a ssessments/

[4] Palomba, C. and Banta, T.W. (1999) Assessment Essentials: Planning, Implementing, and Improving Assessment in Higher Education. Jossey-Bass, Inc., San Francisco.

[5] Banta, T., Griffin, M., Flateby, T. and Kahn, S. (2009) Three Promising Alternatives for Assessing College Students' Knowledge and Skills. National Institute for Learning Outcomes Assessment.

http://learningoutcomesassessment.org/documents/AlternativesforAssessment.pdf

[6] Blooms Taxonomy. (2016). https://cft.vanderbilt.edu/guides-sub-pages/blooms-taxonomy/

[7] BusinessDictionary.com. (2013) Web Finance Inc. http://www.businessdictionary.com/definition/mathematical-model.html

Submit or recommend next manuscript to SCIRP and we will provide best service for you:

Accepting pre-submission inquiries through Email, Facebook, LinkedIn, Twitter, etc. A wide selection of journals (inclusive of 9 subjects, more than 200 journals) Providing 24-hour high-quality service User-friendly online submission system Fair and swift peer-review system Efficient typesetting and proofreading procedure Display of the result of downloads and visits, as well as the number of cited articles Maximum dissemination of your research work

Submit your manuscript at: http://papersubmission.scirp.org/

Or contact jss@scirp.org 